\title{
Serum survivin predicts responses to treatment in active rheumatoid arthritis: a post hoc analysis from the SWEFOT trial
}

\author{
Adrian Levitsky ${ }^{1 *}$, Malin C. Erlandsson ${ }^{2}$, Ronald F. van Vollenhoven ${ }^{1 \dagger}$ and Maria I. Bokarewa ${ }^{2 \dagger}$
}

\begin{abstract}
Background: The identification of biomarkers that predict optimal and individual choices of treatment for patients with rheumatoid arthritis gains increasing attention. The purpose of this study was to investigate if the proto-oncogene survivin might aid in treatment decisions in early rheumatoid arthritis.

Methods: Serum survivin levels were measured in 302 patients who completed the Swedish pharmacotherapy (SWEFOT) trial at baseline, 3, 12, and 24 months. Survivin levels $>0.45 \mathrm{ng} / \mathrm{mL}$ were considered positive. Based on the survivin status, core set outcomes measuring disease activity, functional disability, as well as global health and pain were evaluated after methotrexate (MTX) monotherapy at 3 months, and at 12 and 24 months of follow-up. Treatment of non-responders was randomly intensified with either a combination of disease-modifying antirheumatic drugs (triple therapy: MTX, sulfasalazine, and hydroxychloroquine) or by adding antibodies against tumor necrosis factor (anti-TNF).
\end{abstract}

Results: Antirheumatic treatment resulted in an overall decrease of serum survivin levels. Survivin-positive patients at baseline who initially responded to MTX had a higher risk of disease re-activation (OR 3.21 (95 \% Cl 1.12-9.24), $P=0.032)$ and failed to improve in their functional disability $(P=0.018)$ if having continued on MTX monotherapy compared to survivin-negative patients. Ever-smokers who were survivin-positive were less likely to respond to MTX than those who were survivin-negative (OR $1.91(1.01-3.62), P=0.045)$. In survivin-positive patients, triple therapy led to better improvements in disease activity than did MTX + anti-TNF. At 24 months, survivin-positive patients randomized to anti-TNF had a higher risk of active disease than those randomized to triple therapy (OR $3.15(1.09-9.10), P=0.037$ ).

Discussion: We demonstrate for the first time that survivin is a valuable serologic marker that can distinguish drugspecific clinical responses in early rheumatoid arthritis through the pragmatic clinical setting of the care-based SWEFOT trial. Although treatment response cannot solely be attributable to survivin status, per protocol sensitivity analyses confirmed the superior effect of triple therapy on survivin-positive patients.

Conclusions: Survivin-positive patients have poor outcomes if treated with MTX monotherapy. A decrease of survivin levels during treatment is associated with better clinical responses. For survivin-positive patients who fail MTX, triple therapy is associated with better outcomes than anti-TNF therapy.

Trial registration: WHO database at the Karolinska University Hospital: CT20080004; ClinicalTrials.gov: NCT00764725, registered 1 October 2008.

Keywords: Rheumatoid arthritis, Biomarkers, Survivin, Methotrexate, Disease-modifying antirheumatic drugs, Anti-TNF, Disease activity, Functional disability

\footnotetext{
* Correspondence: adrian.levitsky@ki.se

${ }^{\dagger}$ Equal contributors

'Unit for Clinical Therapy Research, Inflammatory Diseases (ClinTRID),

Karolinska Institutet, D1:00, Karolinska University Hospital, 17176 Stockholm,

Sweden

Full list of author information is available at the end of the article
}

\section{Ciomed Central}

(c) 2015 Levitsky et al. Open Access This article is distributed under the terms of the Creative Commons Attribution 4.0 International License (http://creativecommons.org/licenses/by/4.0/), which permits unrestricted use, distribution, and reproduction in any medium, provided you give appropriate credit to the original author(s) and the source, provide a link to the Creative Commons license, and indicate if changes were made. The Creative Commons Public Domain Dedication waiver (http://creativecommons.org/publicdomain/zero/1.0/) applies to the data made available in this article, unless otherwise stated. 


\section{Background}

Despite advances in antirheumatic treatment, rheumatoid arthritis (RA) continues to be associated with a significant disease burden due to reduced quality of life [1], functional disability [2], and an enhanced prevalence of comorbidities [3, 4]. Marked individual heterogeneity with respect to specific genetic and environmental load, autoantibody production, and cellular, cytokine and gene expression profiles of the inflamed synovia strongly suggests that a more personalized choice of antirheumatic treatment would yield considerably better results. A requirement of biomarkers and algorithms capable of predicting treatment response and reducing unnecessary expenses on the costs of inefficient medication has recently been given high priority [5].

Methotrexate (MTX) is recommended as the top firstline antirheumatic drug owing to its relatively high efficacy and low rate of adverse events [6]. The combination of MTX with glucocorticoids [7], other conventional antirheumatic drugs [8], or with inhibitor of tumor necrosis factor (anti-TNF) $[9,10]$ could be more effective than MTX monotherapy. For patients who fail initial MTX therapy several reasonable options are available, including the addition of sulfasalazine (SSZ) and hydroxychloroquine (HCQ) - the so-called 'triple therapy' (TT) - or the addition of anti-TNF. The Swedish pharmacotherapy (SWEFOT) trial was a standard care-based study [11], where all patients initially received open-label MTX monotherapy followed by randomized treatment with either TT or with MTX in combination with anti-TNF (in this case, infliximab) in the patients who failed to achieve low disease activity on MTX. The trial showed that antiTNF was clinically superior to TT after 12 months, while the difference between the treatment arms leveled-off after 24 months [12]. Recent randomized controlled trials, which compared the combination of conventional diseasemodifying drugs with biologic strategies, demonstrated that both treatment options can be successful for some patients $[13,14]$. The results of randomized and observational studies $[15,16]$ indicated a substantial difference in social care costs for these treatment alternatives. Thus, exponential increases in expenses urge reliable indicators that would predict the optimal treatment choice for every patient.

The proto-oncogene survivin is a biomarker of cancer and may be found in most tumor tissues, such as lymphoma, colorectal carcinoma, breast cancer, small cell lung adenocarcinoma, and others [17-20], where it predicts prognosis and the potential for metastasis. Cellular functions of survivin comprise inhibition of apoptosis in the cytoplasmic and mitochondrial compartments by preventing activation of caspases, and regulation of the cell cycle progression in the nucleus by aiding formation of a chromosomal passenger complex [21, 22]. In healthy tissues, survivin expression is indispensable for cell renewal and differentiation, being consistently expressed in thymocytes, bone marrow hematopoietic progenitors and stem cells, cells of the colon epithelium, and vascular endothelial cells [23-25].

In RA, serum survivin has recently emerged as a marker of the disease. It is over-expressed in the preclinical phase of RA, and, together with antibodies to citrullinated peptides, is predictive for development of RA several years ahead of clinical symptoms [26]. Importantly, in the pre-symptomatic stage of RA, survivin was associated with the pattern of regulatory cytokines (interleukin (IL)-12, IL-1, IL-9, granulocyte-macrophage colony-stimulating factor, and IL-2) controlling the formation of pathogenic T helper (Th) 1 and Th17 lymphocytes. Also, survivin has been recently connected to carriage of the human leukocyte antigen (HLA) DRB1 genotype and smoking [27, 28], important keystones in the pathogenesis of RA. Survivin is critical for the process of antigen presentation - the breaking point of immune responses in RA, being required for the expression of major histocompatibility complex class II molecule receptors on dendritic cells [29] and for the formation of functional $\mathrm{T}$ cell receptors [30, 31]. Expression of survivin in B cells might be attributable to adverse cell recognition in RA, since changes in survivin expression after therapeutic B cell depletion was associated with a reduction of $B$ cell numbers, serum levels of rheumatoid factor (RF) and the activity of arthritis [32]. In observational study cohorts, survivin assists with the early recognition of RA patients with poor prognosis, being associated with progressive joint damage and a low rate of treatment response [33-35]. The role of survivin as a clinical predictor of drug-specific treatment response has not been investigated in RA. Therefore, the design of the SWEFOT trial provided an opportunity for the simultaneous evaluation of clinical outcomes of different antirheumatic treatment strategies with respect to the survivin status of the patients. In this post hoc analysis we asked if high levels of survivin in serum identified RA patients with poor response to antirheumatic treatment and worse clinical outcomes over time.

\section{Methods \\ Study design}

The SWEFOT trial is an open-label randomized study comparing treatment strategies in patients with early RA [12]. Patients from 15 rheumatology units in Sweden with symptom duration $<1$ year and previously not treated with disease-modifying antirheumatic drugs were invited to participate in this trial. At inclusion, 487 patients with the 28-joint count disease activity score (DAS28) $>3.2$ were enrolled in the trial between December 2002 and 2006 (Fig. 1). All patients were initially treated with 


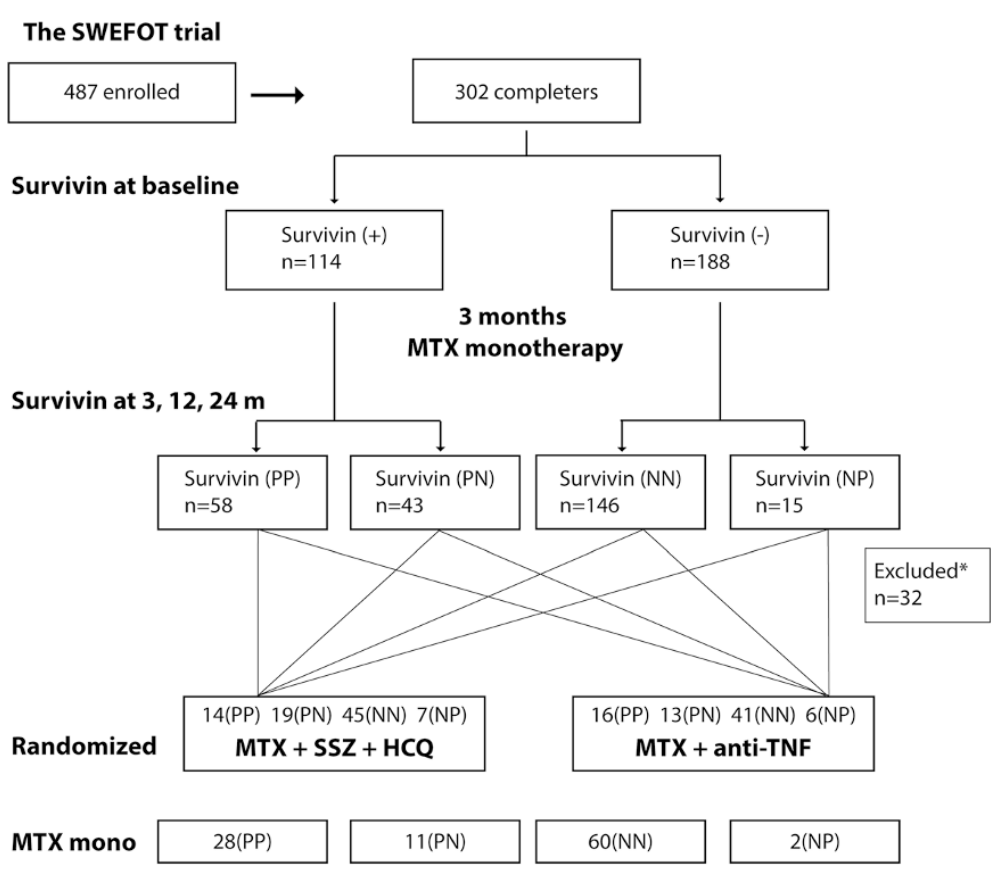

Fig. 1 Analysis profile. Serum levels of survivin were measured from samples of 302 patients who completed the 24-month follow-up of the SWEFOT trial. Measurements at baseline resulted in the survivin-positive $(>0.45 \mathrm{ng} / \mathrm{mL})$ and survivin-negative patient groups. Measurements at 3 , 12, and 24 months identified patients who decreased or increased their serum survivin levels at any time point over 24 months. Four groups of patients were formed and compared: patients positive for survivin (PP), or negative for survivin (NN) on all testing occasions; and patients survivinpositive at baseline who converted negative (PN), or survivin-negative patients who converted positive (NP). After 3 months of methotrexate (MTX) monotherapy, patients still with active disease were randomized to triple therapy (MTX + sulfasalazine (SSZ) + hydroxychloroquine (HCQ)) or to anti-TNF (MTX + infliximab). *Patients with missing samples at 12 and 24 months $(n=15)$, who were not randomized $(n=2)$, or who changed their survivin status on several occasions $(n=15)$ were excluded from analysis

methotrexate (MTX, $20 \mathrm{mg} /$ week). Clinical assessment at 3 months distinguished patients with DAS28 $\leq 3.2$ (MTX responders) and DAS28 $>3.2$ (MTX non-responders). MTX responders continued treatment with MTX monotherapy, while MTX non-responders were randomized to TT $(\mathrm{MTX}+\mathrm{SSZ}+\mathrm{HCQ})$ or to anti-TNF therapy (MTX + infliximab). Clinical assessment of the patients was performed at baseline and thereafter at 3, 12, and 24 months using the DAS28 and other 'core set' outcomes, including functional disability measured by the Health Assessment Questionnaire (HAQ), pain perception graded by visual analog scale (pain-VAS), and patient's global assessment of disease activity (PtGA-VAS). A total of 302 patients completed the 24-month trial period by intention-to-treat and were the subjects for this analysis.

The study protocol was approved by the regional ethical committees of Sweden. The SWEFOT trial has registration identification CT20080004 at the World Health Organization (WHO) database at the Karolinska University Hospital, Stockholm, and registration identification NCT00764725 at ClinicalTrials.gov. At enrollment, all patients gave their written informed consent to participate in the study.

\section{Measurements of serum survivin levels}

Blood samples were obtained at baseline before MTX treatment, and at 3 months for all patients enrolled in the SWEFOT trial. At 12 and 24 months, samples for the MTX non-responders were available. Samples were centrifuged and stored at $-80{ }^{\circ} \mathrm{C}$.

Serum survivin levels were measured using a matchedantibody pair (rabbit anti-human survivin) by a sandwich enzyme-linked immunosorbent assay (DYC647, R\&D Systems, Minneapolis, MN, USA) [33, 36]. The detection limit of the assay was $0.1 \mathrm{ng} / \mathrm{mL}$. The cut-off level of $0.45 \mathrm{ng} / \mathrm{mL}$ was set as previously reported [29], and was used to distinguish between survivin-positive $(+)$ and survivin-negative (-) patients.

\section{Statistical analysis}

The statistical analyses were based on intention-to-treat, last observation carried forward. Changes in survivin status after 3 months of MTX treatment resulted in the formation of four survivin groups: survivin-positive $(+/+)$; survivin-negative $(-/-)$; survivin converting to negative $(+/-)$; and survivin converting to positive $(-/+)$. 
Patients who changed survivin more than once $(\mathrm{n}=15)$ were excluded from the analysis.

Utilizing IBM SPSS v.22.0, and OpenEpi.com [37], nonparametric statistical comparisons were performed. Data is presented as the median and interquartile range (IQR) for continuous variables, and frequency (\%) or odds ratio (OR) (95\% confidence interval, CI) for proportions. Mann-Whitney U tests and Wilcoxon signedrank tests were used to compare continuous variables, whereas Pearson's $\chi^{2}$ or Fisher's exact tests were utilized for proportions. For the comparison of more than two groups, initial analysis was done by Kruskal-Wallis tests, followed by pairwise post hoc analyses by DunnBonferroni correction. All tests were two-tailed and performed at the 0.05 level of significance.

\section{Results}

Changes of serum survivin levels during the SWEFOT trial At baseline, 114 of 302 patients (38\%) were survivinpositive $(+)$. The survivin $(+)$ patients were significantly more often RF $(+)$ and tended to have higher functional disability by HAQ compared to survivin (-) patients (Table 1). There were no differences in baseline disease activity by DAS28 or any other core set clinical outcomes. Serum survivin levels decreased significantly from baseline over 24 months (Fig. 2). The majority of

Table 1 Baseline clinical characteristics of patients with early RA enrolled into SWEFOT, divided by survivin status

\begin{tabular}{|c|c|c|c|}
\hline \multirow[t]{2}{*}{ Variables } & \multirow{2}{*}{$\begin{array}{l}\text { Survivin-positive } \\
\mathrm{n}=114\end{array}$} & \multirow{2}{*}{$\begin{array}{l}\text { Survivin-negative } \\
\mathrm{n}=188\end{array}$} & \multirow[t]{2}{*}{$P$ value } \\
\hline & & & \\
\hline Age (years) & $56.0(43.0,62.25)$ & $57.0(44.0,67.0)$ & 0.332 \\
\hline $\operatorname{Sex}(F)$ & 77 (68 \%) & 143 (76 \%) & 0.107 \\
\hline Duration & $5.0(4.0,8.0)$ & $5.0(4.0,8.75)$ & 0.905 \\
\hline $\mathrm{RF}(+)$ & 91/113 (81 \%) & 108/187 (58 \%) & $<0.001$ \\
\hline Anti-CCP (+) & 71/107 (66 \%) & 103/183 (56 \%) & 0.091 \\
\hline Pain-VAS & $60.0(45.75,72.0)$ & $54.0(39.0,71.0)$ & 0.269 \\
\hline PtGA-VAS & $60.0(39.0,77.0)$ & $58.0(35.25,74.0)$ & 0.452 \\
\hline HAQ & $1.25(0.85,1.75)$ & $1.0(0.75,1.5)$ & 0.079 \\
\hline TJC & $8.0(5.0,13.0)$ & $9.5(6.0,14.0)$ & 0.134 \\
\hline SJC & $11.0(6.0,14.0)$ & $10.0(7.0,14.0)$ & 0.692 \\
\hline ESR & $35.0(21.5,63.0)^{a}$ & $34.0(19.25,50.0)$ & 0.260 \\
\hline CRP & $17.0(9.0,54.5)^{a}$ & $18.0(9.0,37.0)$ & 0.628 \\
\hline DAS28 & $5.78(5.06,6.35)^{\mathrm{a}}$ & $5.72(5.02,6.43)$ & 0.751 \\
\hline
\end{tabular}

${ }^{a}$ Number of patients, $\mathrm{n}=113$. Serum levels of survivin $>0.45 \mathrm{ng} / \mathrm{mL}$ indicate survivin-positive patients. Statistics in the groups are presented as medians and interquartile range (IQR). Comparisons between the groups were done by Mann-Whitney $\mathrm{U}$ tests for continuous variables, and by Pearson's $X^{2}$ tests for frequencies. Anti-CCP, antibodies to cyclic citrullinated peptides; CRP, C-reactive protein; DAS28, 28-joint count disease activity score; ESR, erythrocyte sedimentation rate; F, females; $\mathrm{HAQ}$, Health Assessment Questionnaire; pain-VAS, visual analog scale for pain; PtGA-VAS, patient's global assessment of disease activity; RA, rheumatoid arthritis; RF, rheumatoid factor; SJC, swollen joint count; TJC, tender joint count

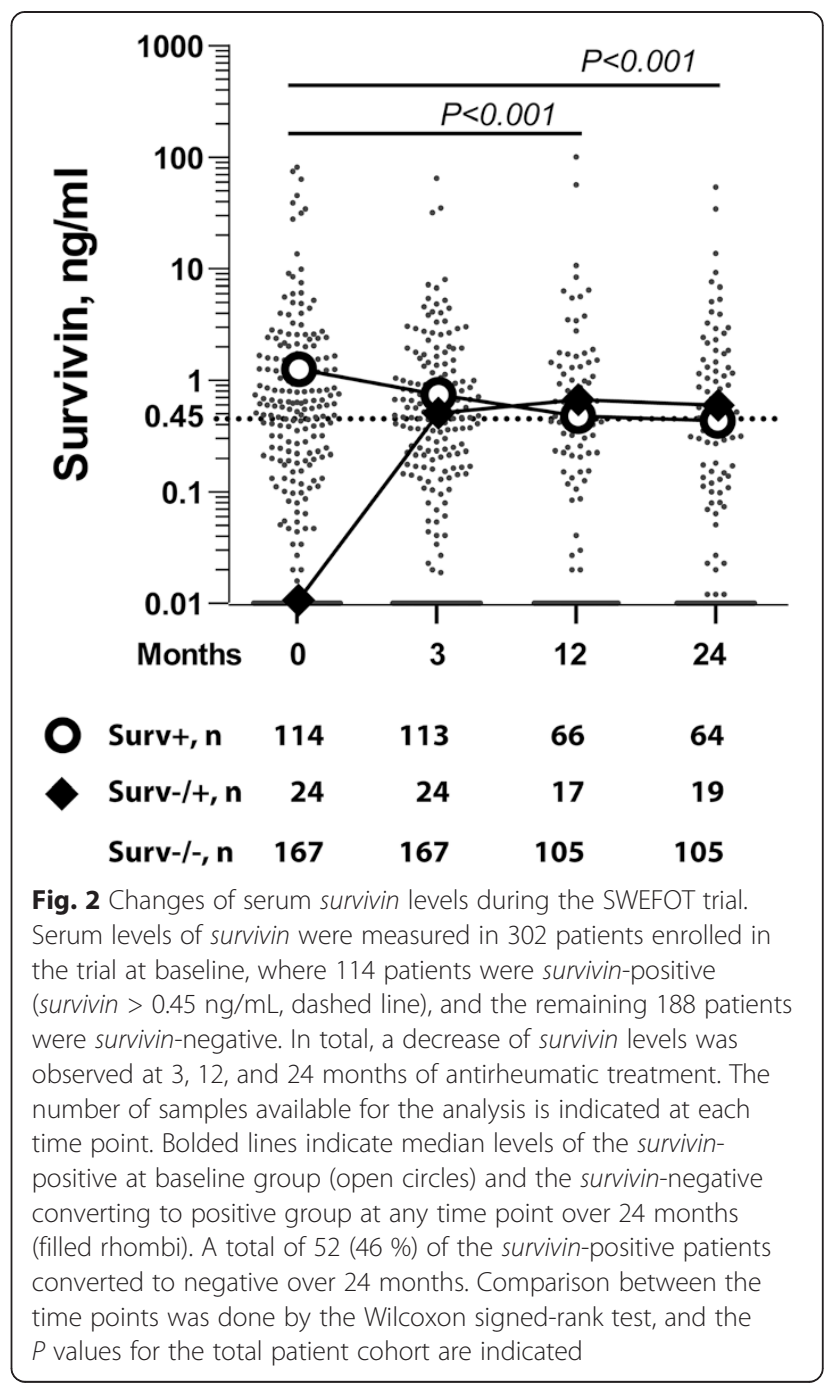

patients (167/294, $56.8 \%)$ remained survivin-negative $(-/-)$ by 3 months, and 75 patients remained survivinpositive $(+/+)$. Thirty-eight patients converted to negative $(+/-)$ by 3 months and an additional 14 patients converted to negative $(+/-)$ by 24 months. Of the initially survivin (-) patients, 24/188 (12.8 \%) became survivin-positive $(-/+)$ at any time point over 24 months (Fig. 2). The clinical significance of the change in survivin levels with respect to the core set outcomes was assessed for the survivin $(+/+),(+/-),(-/-)$, and $(-/+)$ groups (Fig. 1).

\section{Clinical outcomes with MTX monotherapy}

After 3 months of MTX treatment, there were 101 MTX responders and 193 MTX non-responders with available survivin status. As reported, the MTX responders had significantly better treatment outcomes compared to non-responders with respect to DAS28 and other clinical outcomes $(P<0.001)[11,12,38]$. Thirty-nine of 101 (38\%) MTX responders were survivin (+), and so were 
74 of 193 (38\%) MTX non-responders. Since high levels of survivin were associated with smoking [27, 39], we analyzed if the response to treatment was dependent on the smoking habits of the patients. The prevalence of ever-smokers was similar among survivin (+) (68\%) and (-) (61\%) patients at baseline. Among the ever-smokers, survivin (+) patients had a higher probability to be MTX non-responders compared to survivin (-) patients (51/ 71 versus 64/112, OR 1.91 (95\% CI 1.01-3.62), $P=$ $0.045)$. Survivin conversion to negative (+/-) occurred without a difference between ever- and never-smokers (23/165 versus 13/96).

At 3 months, the survivin (+/+) MTX responders had a higher HAQ compared to those who converted negative $(+/-)$, indicating a delay in improvement of their functional disability (Fig. 3a). This higher HAQ was not directly related to the disease activity, since the survivin $(+/+)$ patients had no significant differences in DAS28, pain-VAS, and PtGA-VAS at 3 months when compared to the other survivin groups.

Among initial MTX responders who continued on MTX monotherapy, survivin (+) patients had a higher risk of disease reactivation (DAS28 $>3.2$ ) at 12 months compared to survivin (-) patients (12/36 versus $7 / 52$, OR 3.21 (1.12-9.24), $P=0.032)$. Also, survivin $(+/+)$ patients on MTX monotherapy had significantly higher DAS28, HAQ, and PtGA-VAS compared to the survivin $(-/-)$ patients (Fig. 3a). This difference was maintained at 24 months compared to the survivin $(+/-)$ and $(-/-)$ subgroups (Fig. 3a).

\section{Clinical outcomes with combined antirheumatic treatments}

MTX non-responders were randomized to TT $(n=85)$ or to anti-TNF $(\mathrm{n}=76)$ treatment. At 12 months, the TT-treated survivin $(+/-)$ subgroup $(\mathrm{n}=19)$ had better outcomes compared to the survivin $(-/+)$ subgroup $(\mathrm{n}=7)$ in DAS28, pain-VAS and in PtGA-VAS (Fig. 3b), and had significantly lower DAS28 and pain-VAS compared to anti-TNF-treated survivin $(+/-)$ patients $(\mathrm{n}=13)$ (median (IQR) $2.34(1.94,3.56)$ versus 3.43 (2.82, 4.96), $P=0.045$; and $21.0(10.0,38.0)$ versus $35.0(24.5,59.0)$, $P=0.033$, respectively). Among anti-TNF-treated patients, the survivin subgroups had no differences in core set outcomes (Fig. 3c).

At 24 months, better clinical outcomes were found among the survivin $(+)$ patients at baseline $((+/+)$ and $(+/-), \mathrm{n}=14+19)$ randomized to TT compared to the survivin $(+)$ patients $(\mathrm{n}=16+13)$ randomized to antiTNF. The TT-treated survivin (+) patients attained a significantly lower DAS28 (2.37 $(1.79,3.27)$ versus 3.50 (2.05, 4.63), $P=0.020$ ), and the estimated risk of active disease activity (DAS28 $>3.2$ ) was higher among the anti-TNF-treated survivin (+) patients (55\% versus $28 \%$;
OR 3.15 (95 \% CI 1.09-9.10), $P=0.037$ ) (Fig. 4). Consequently, the prevalence of DAS28 $<3.2$ among the TT-treated survivin (+) patients was similar to MTX responders ( $72 \%$ and $75 \%$, respectively). Analogously, TT-treated survivin $(+/+)$ patients $(\mathrm{n}=14)$ had a lower pain-VAS compared to anti-TNF-treated survivin $(+/+)$ patients $(\mathrm{n}=16)(14.0(3.75,23.0)$ versus $33.0(15.0,66.0)$, $P=0.038)$, and the survivin $(+/-)$ patients treated with anti-TNF had a high frequency of active disease compared to the TT-treated subgroup (62\% versus $26 \%, P=0.046$ ). Survivin (-/-) patients showed similar responses to TT and anti-TNF treatment and reached comparable DAS28, HAQ, pain-VAS, and PtGA-VAS outcomes (Fig. 3b,c). The proportion of patients with DAS > 3.2 among MTX responders and survivin $(-)$ at baseline $((-/-)$ and $(-/+)$, $\mathrm{n}=51+1)$ was always lower when compared to survivin (-) MTX non-responders $(\mathrm{n}=83+13)$ (Fig. 4). The survivin $(-/+)$ patients treated with TT and anti-TNF had similar outcomes.

\section{Discussion}

We studied the importance of serum survivin levels during antirheumatic treatment by post hoc analysis of the SWEFOT trial cohort. Our results confirm that patients survivin-positive at baseline can have poor long-term outcomes. Patients who remain positive by 3 months, despite initially responding by DAS28, are recognized by a risk for later disease reactivation and possess early functional disability that deteriorates even further over 24 months. These findings support the previously reported association between radiographic damage and a considerable gain in HAQ over time despite clinical remission [40]. It also may at least in part explain the observations from the BARFOT cohort indicating significantly higher 60-month disease activity and radiographic progression in survivin-positive early RA patients [27]. Notably, the survivin-positive patients within the BARFOT and SWEFOT cohorts of early RA patients had comparable levels of DAS and HAQ at 24-month followup despite obvious differences in therapeutic choices and significantly higher remission rates reached by groups with different survivin status within the SWEFOT trial.

Female gender, age, current smoking, and functional disability as predictors of MTX response were previously established [41]. We extend the list of predictors with survivin measurements and show that survivin binds together as an environmental risk represented by smoking, with clinical parameters of disease activity and functional disability. Concerning the analysis of survivin groups, neither the presence of RF or antibodies against citrullinated peptides, nor the combined multi-biomarker disease activity score [42] supported discrimination in the disease outcome achieved by survivin measurements (results not shown). Taken in concert, these observations confirm the 


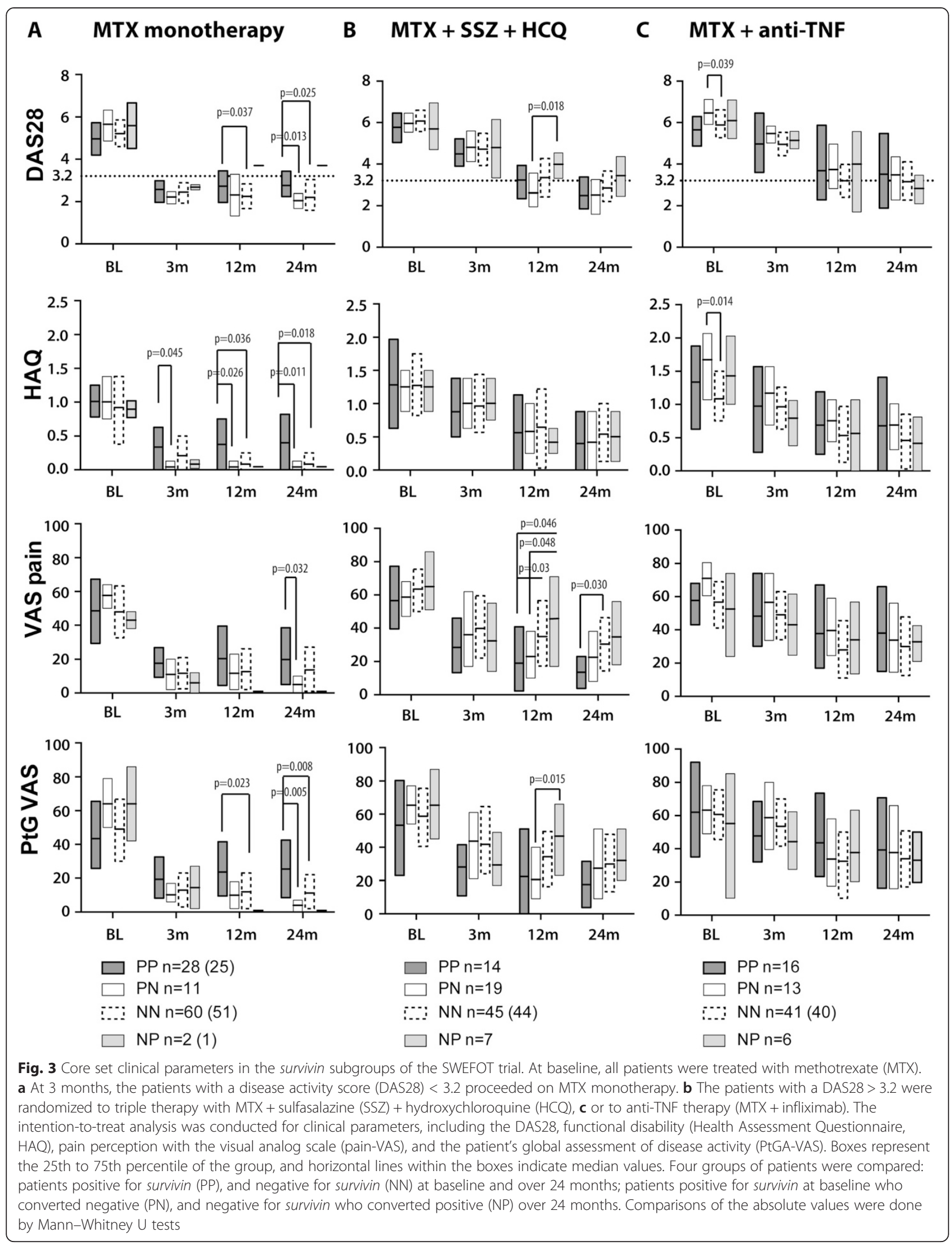




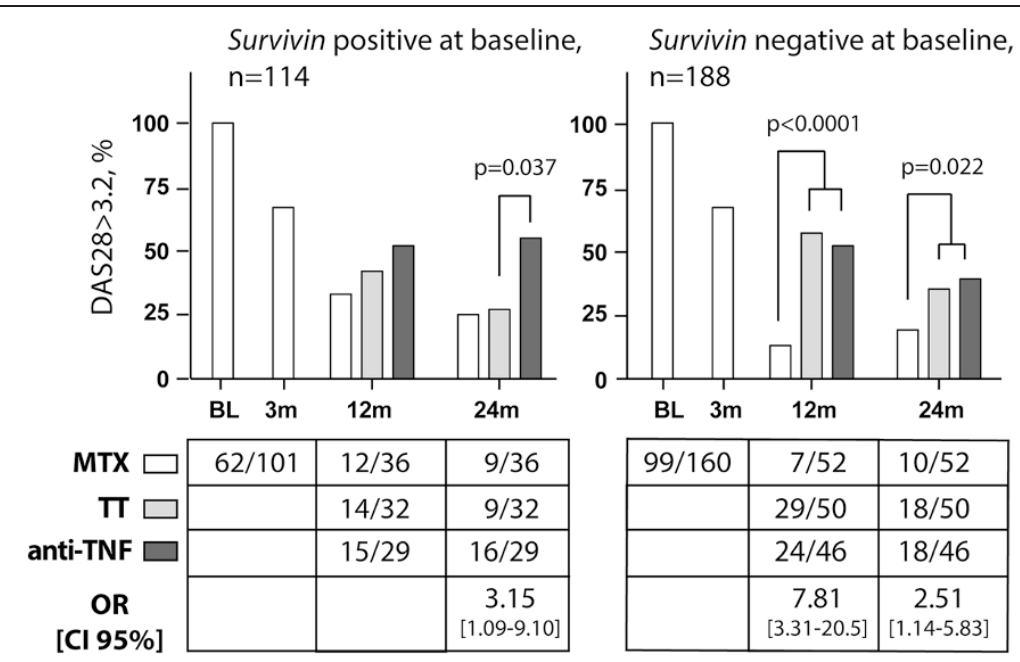

Fig. 4 Prevalence of active disease among survivin-positive or survivin-negative patients in the SWEFOT trial. The prevalence of active disease (disease activity score, DAS28 > 3.2) among patients who were survivin-positive or survivin-negative at baseline is presented for the groups treated with methotrexate (MTX) monotherapy and the groups randomized to triple therapy (TT) or to anti-TNF therapy. Comparisons were done by Pearson's $X^{2}$ or Fisher's exact tests, and odds-based estimates (odds ratio, OR) and $95 \%$ confidence intervals (CI) are indicated. Two patients with no available DAS28 at 3 months were excluded from the analysis

independent predictive value of survivin measurements in early RA and suggest that survivin-positive patients require initial combination treatment to avoid potentially irreversible outcomes.

The other important finding of this study is related to the choice of treatment after failure to respond adequately to MTX. The primary response to MTX and early remission remained a major predictor of long-term clinical outcomes for patients in the SWEFOT trial, and the combined intensive treatment for MTX nonresponders in this trial was not sufficient for achieving the same outcomes. The importance of MTX response has been initially reported in randomized goal-steered treatment studies $[43,44]$ and repeated by observational studies [45, 46] and a meta-analysis [47]. Our data show that for survivin-positive patients, TT is an effective treatment option with a rate of remission in this group comparable to the MTX responder group. Surprisingly, anti-TNF treatment appeared to be less successful for survivin-positive MTX non-responders.

Several approaches to understanding the nature of poor anti-TNF response have been proposed, where genetic variations and TNF-independent mechanisms of arthritis have been extensively explored. Despite extensive candidate gene-driven and whole-genome based research, presenting several loci involved in anti-TNF treatment response, no sustainable solutions have currently been found [48-50]. In addition, attempts to identify autoantibody and cytokine profiles suggest a potential predictive signature $[42,51,52]$, although, in light of these promising results, the practical value remains yet to be elucidated.
The SWEFOT trial demonstrates that survivin is a changeable serologic marker with a notable connection to disease outcome. A decrease of serum survivin levels is shown to be an overall consequence of antirheumatic treatment, and serological conversion to survivin-negative occurred in about a half of the survivin-positive patients. Most of the survivin conversion was identified after 3 months of MTX monotherapy. It was coupled with excellent clinical outcomes and a low reactivation rate at follow-up. In contrast, patients who gained survivinpositivity were comprised almost solely of MTX nonresponders with poor outcomes, irrespective of treatment modality. For the first time, survivin status and conversion have been associated with clinical manifestations of early RA in a pragmatic clinical setting of the broad care-based SWEFOT trial. In the original report [11], the anti-TNF group was shown to provide significantly better clinical responses and non-significantly different radiographic outcomes in comparison to TT at 12 months, which was reversed at 24 months [12]. Now, we identify a subgroup of survivin-positive patients not responding effectively to anti-TNF therapy. Thus, the monitoring of survivin levels assists in prognosis and treatment decisions for patients with early RA.

The nature of extracellular survivin release remains an enigma. Since active extracellular transport of survivin is described only as exosomal content [53], profound cellular disruption could be a cause of intermittent serum levels of survivin. The poor response to anti-TNF treatment observed in this study and lack of a direct correlation between serum survivin and inflammatory markers, including C-reactive protein and IL-6 [29, 33, 54], suggests 
a TNF-independent mechanism of survivin release. Extracellular survivin has been shown to be biologically active inducing surface expression of adhesion molecules on leukocytes of RA patients [55] with a potential to regulate $\mathrm{T}$ cell functions and motility through a broad net of intracellular effectors [56, 57]. At the preclinical stage of arthritis, serum survivin has been associated with the release of cytokines controlling the formation of Th cell subsets Th1 and Th17 [26, 58]. Inhibition of survivin in experimental arthritis proved its intimate relation to the formation of effector $\mathrm{T}$ cells and to the system of matrix proteases in the inflamed joints $[54,59]$. The processes triggering and abrogating survivin release in RA could therefore pave a way to efficient therapeutic control of the disease.

Several points in the specificity of this analysis could have influenced the results. The SWEFOT trial does not account for patients changing treatment by adjusting drug doses or switching to cyclosporine A for the TT group or etanercept for the anti-TNF group due to toxicity. Drug cytotoxicity could be responsible for diseaseindependent survivin release, although the number of such patients was small. Also, a group of patients with frequently changeable survivin status were excluded from statistical analysis. The analysis does not account for the autoantibody status within the survivin groups, since no association between the presence of autoantibodies and a decrease of survivin levels was noted after 3 months of MTX monotherapy. Combined survivin and autoantibody analysis could have strengthened the obtained results due to the tight coexistence of these biomarkers in severe RA [27, 28]; however, it could have given the opposite result due to the association of autoantibodies with a strong response to anti-TNF treatment [52]. The limited final numbers of patients allocated and followed-up within the TT- and anti-TNF-treated groups do not permit a complete exclusion of a serendipitous outcome. Nonetheless, the SWEFOT study was adequately powered to address whether survivin could be a predictor of response, with the utilization of robust nonparametric statistical methods - and sensitivity analyses of the patients who completed the study per protocol confirmed the superior effect of TT on survivin-positive patients. Finally, it is important to keep in mind that poor outcomes among the groups of MTX non-responders are not restricted to survivin status. A substantial number of survivin-negative patients failed to respond to TT and anti-TNF treatment for reasons yet unknown.

\section{Conclusions}

Our results indicate that the measurement of serum survivin is useful for planning treatment strategies in patients with early RA. High levels of survivin identify patients with a worse prognosis and a risk for disease reactivation attended by deteriorating functional disability while on MTX monotherapy, whereas the combination of synthetic disease-modifying drugs appears to be more effective than a biological treatment strategy with anti-TNF.

\section{Abbreviations}

Cl: Confidence interval; DAS28: 28-joint count disease activity score; HAQ: Health Assessment Questionnaire; HCQ: Hydroxychloroquine; HLA: Human leukocyte antigen; IL: Interleukin; IQR: Interquartile range; MTX: Methotrexate; OR: Odds ratio; PtGA: Patient's global assessment of disease activity; RA: Rheumatoid arthritis; RF: Rheumatoid factor; SSZ: Sulfasalazine; SWEFOT trial: Swedish pharmacotherapy trial; Th: T helper cells; TNF: Tumor necrosis factor; TT: Triple therapy; VAS: Visual analog scale; WHO: World Health Organization

\section{Competing interests}

$A L, M E$, and $M B$ have no competing interests to disclose. RVV has received grants/research support from AbbVie, Bristol-Myers Squibb, GlaxoSmithKline, Pfizer, Roche, and UCB; and consultancy fees from AbbVie, Biotest, BristolMyers Squibb, Crescendo, GlaxoSmithKline, Janssen, Lilly, Merck, Pfizer, Roche, $\mathrm{UCB}$, and Vertex; outside the submitted work.

\section{Authors' contributions}

AL and ME prepared samples, performed statistical analyses, and prepared the manuscript. ME measured survivin levels from the delivered samples. MB and RvV conceived the project, designed the analysis of the results, and interpreted the results. MB and RvV contributed equally to this study. All authors participated in the discussion of the results and preparation of the manuscript. All authors read and approved the final version of the manuscript.

\section{Authors' information}

AL is a Research Technician and PhD Student at the Unit for Clinical Therapy Research, Inflammatory Diseases (ClinTRID), Karolinska Institutet, Stockholm, Sweden; ME is a Postdoctoral Researcher at the Department of

Rheumatology and Inflammation Research, Sahlgrenska University Hospital and Gothenburg University, Gothenburg, Sweden; RvV is a Professor of Rheumatology and Chief of the ClinTRID Unit, Karolinska Institutet, Stockholm, Sweden; and MB is a Professor of Rheumatology at the Department of Rheumatology and Inflammation Research, Sahlgrenska University Hospital and Gothenburg University, Gothenburg, Sweden.

Availability of data and materials

Not applicable.

\section{Acknowledgments}

We thank Karen Hambardzumyan for assistance, and acknowledge all patients, physicians, and nurses who made the SWEFOT trial possible. This work has been funded by grants from the Swedish Research Council (521-2011-2414 to MB), the Swedish Association against Rheumatism, King Gustaf V:s 80-year Foundation, the Professor Nanna Swartz Foundation, the Torsten Söderberg's Foundation, Rune and Ulla Amlöv's Trust, the Ingabritt and Arne Lundberg's Foundation, the University of Gothenburg, and the Regional agreement on medical training and clinical research between the Western Götaland county council and the University of Gothenburg (ALFGBG-138661). MB holds the Medical Society of Gothenburg Chair in Rheumatology (Ingrid Högbergs Fond). The funding sources had no involvement in study design; in the collection, analysis and interpretation of data; in the writing of the report; or in the decision to submit the article for publication.

\section{Author details}

'Unit for Clinical Therapy Research, Inflammatory Diseases (ClinTRID), Karolinska Institutet, D1:00, Karolinska University Hospital, 17176 Stockholm, Sweden. ${ }^{2}$ Department of Rheumatology and Inflammation Research, Sahlgrenska University Hospital, University of Gothenburg, Gothenburg, Sweden.

Received: 6 May 2015 Accepted: 10 September 2015

Published online: 30 September 2015 


\section{References}

1. Boonen A, Severens $\mathrm{JL}$. The burden of illness of rheumatoid arthritis. Clin Rheumatol. 2011;30:S3-8

2. Sokka T, Kautiainen H, Pincus T, Verstappen SM, Aggarwal A, Alten R, et al. Work disability remains a major problem in rheumatoid arthritis in the 2000s: data from 32 countries in the QUEST-RA study. Arthritis Res Ther. 2010;12:R42

3. Dougados $M$, Soubrier $M$, Antunez A, Balint $P$, Balsa A, Buch $M H$, et al. Prevalence of comorbidities in rheumatoid arthritis and evaluation of their monitoring: results of an international, cross-sectional study (COMORA). Ann Rheum Dis. 2014;73:62-8.

4. Gabriel SE, Michaud K. Epidemiological studies in incidence, prevalence, mortality, and comorbidity of the rheumatic diseases. Arthritis Res Ther. 2009;11:229.

5. Gerlag DM, Raza K, van Baarsen LG, Brouwer E, Buckley CD, Burmester GR, et al. EULAR recommendations for terminology and research in individuals at risk of rheumatoid arthritis: report from the Study Group for Risk Factors for Rheumatoid Arthritis. Ann Rheum Dis. 2012;71:638-41.

6. Smolen JS, Landewé R, Breedveld FC, Dougados M, Emery P, Gaujoux-Viala $C$, et al. EULAR recommendations for the management of rheumatoid arthritis with synthetic and biological disease-modifying antirheumatic drugs. Ann Rheum Dis. 2010;69:964-75.

7. Gaujoux-Viala C, Nam J, Ramiro S, Landewe R, Buch MH, Smolen JS, et al. Efficacy of conventional synthetic disease-modifying antirheumatic drugs, glucocorticoids and tofacitinib: a systematic literature review informing the 2013 update of the EULAR recommendations for management of rheumatoid arthritis. Ann Rheum Dis. 2014;73:510-5.

8. Katchamart W, Trudeau J, Phumethum V, Bombardier C. Methotrexate monotherapy versus methotrexate combination therapy with non-biologic disease modifying anti-rheumatic drugs for rheumatoid arthritis. Cochrane Database Syst Rev. 2010;4, CD008495.

9. Kuriya B, Arkema EV, Bykerk VP, Keystone EC. Efficacy of initial methotrexate monotherapy versus combination therapy with a biological agent in early rheumatoid arthritis: a meta-analysis of clinical and radiographic remission. Ann Rheum Dis. 2010;69:1298-304.

10. Ma MH, Kingsley $\mathrm{GH}$, Scott DL. A systematic comparison of combination DMARD therapy and tumour necrosis inhibitor therapy with methotrexate in patients with early rheumatoid arthritis. Rheumatology. 2010:49:91-8.

11. van Vollenhoven RF, Ernestam S, Geborek P, Petersson IF, Cöster L, Waltbrand $\mathrm{E}$, et al. Addition of infliximab compared with addition of sulfasalazine and hydroxychloroquine to methotrexate in patients with early rheumatoid arthritis (Swefot trial): 1-year results of a randomised trial. Lancet. 2009:374:459-66.

12. van Vollenhoven RF, Geborek P, Forslind K, Albertsson K, Ernestam S, Petersson IF, et al. Conventional combination treatment versus biological treatment in methotrexate-refractory early rheumatoid arthritis: 2 year follow-up of the randomised, non-blinded, parallel-group Swefot trial. Lancet. 2012;379:1712-20.

13. O'Dell JR, Mikuls TR, Taylor TH, Ahluwalia V, Brophy M, Warren SR, et al. Therapies for active rheumatoid arthritis after methotrexate failure. N Engl J Med. 2013;369:307-18.

14. Scott DL, Ibrahim F, Farewell V, O'Keeffe AG, Walker D, Kelly C, et al. Tumour necrosis factor inhibitors versus combination intensive therapy with conventional disease modifying anti-rheumatic drugs in established rheumatoid arthritis: TACIT non-inferiority randomised controlled trial. BMJ. 2015;350:h1046.

15. Listing J, Strangfeld A, Rau R, Kekow J, Gromnica-Ihle E, Klopsch T, et al. Clinical and functional remission: even though biologics are superior to conventional DMARDs overall success rates remain low-results from RABBIT, the German biologics register. Arthritis Res Ther. 2006:8:R66.

16. Sokka T, Haugeberg G, Asikainen J, Widding Hansen IJ, Kokko A, Rannio T, et al. Similar clinical outcomes in rheumatoid arthritis with more versus less expensive treatment strategies. Observational data from two rheumatology clinics. Clin Exp Rheumatol. 2013:31:409-14.

17. Cho S, Lee JH, Cho SB, Yoon KW, Park SY, Lee WS, et al. Epigenetic methylation and expression of caspase 8 and survivin in hepatocellular carcinoma. Pathol Int. 2010;60:203-11

18. Goossens-Beumer IJ, Zeestraten EC, Benard A, Christen T, Reimers MS, Keijzer R, et al. Clinical prognostic value of combined analysis of Aldh1, Survivin, and EpCAM expression in colorectal cancer. $\mathrm{Br} J$ Cancer. $2014 \cdot 110 \cdot 2935-44$
19. Pickhard A, Grober S, Haug AK, Piontek G, Wirth M, Strassen U, et al. Survivin and pAkt as potential prognostic markers in squamous cell carcinoma of the head and neck. Oral Surg Oral Med Oral Pathol Oral Radiol. 2014;117:733-42

20. Gu YJ, Jin SD, Wang F, Hua YB, Yang L, Shu YQ, et al. Clinicopathological significance of PI3K, Akt and survivin expression in gastric cancer. Biomed Pharmacother. 2014;68:471-5.

21. Altieri DC. Survivin and IAP proteins in cell-death mechanisms. Biochem J. 2010;430:199-205.

22. Athanasoula KC, Gogas H, Polonifi K, Vaiopoulos AG, Polyzos A, Mantzourani M. Survivin beyond physiology: orchestration of multistep carcinogenesis and therapeutic potentials. Cancer Lett. 2014;347:175-82.

23. Ambrosini G, Adida C, Altieri DC. A novel anti-apoptosis gene, survivin, expressed in cancer and lymphoma. Nat Med. 1997:3:917-21.

24. Adida C, Crotty PL, McGrath J, Berrebi D, Diebold J, Altieri DC. Developmentally regulated expression of the novel cancer anti-apoptosis gene survivin in human and mouse differentiation. Am J Pathol. 1998;152:43-9.

25. Fukuda S, Pelus LM. Survivin, a cancer target with an emerging role in normal adult tissues. Mol Cancer Ther. 2006;5:1087-98.

26. Bokarewa M, Brink M, Erlandsson M, Rantapää Dahlqvist S. Survivin but not Fms-like tyrosine kinase 3 ligand is up-regulated before the onset of rheumatoid arthritis: a pilot study. Arthritis Res Ther. 2014:16:R45.

27. Svensson B, Hafström I, Erlandsson MC, Forslind K, Bokarewa MI. Smoking in combination with antibodies to cyclic citrullinated peptides is associated with persistently high levels of survivin in early rheumatoid arthritis: a prospective cohort study. Arthritis Res Ther. 2014;16:R12.

28. Chun-Lai T, Murad S, Erlandsson MC, Hussein H, Sulaiman W, Dhaliwal JS, et al. Recognizing rheumatoid arthritis: oncoprotein survivin opens new possibilities: a population-based case-control study. Medicine (Baltimore). 2015;94:e468.

29. Andersson SEM, Svensson MND, Erlandsson MC, Dehlin M, Andersson KME, Bokarewa Ml. Activation of Fms-like tyrosine kinase 3 signaling enhances survivin expression in a mouse model of rheumatoid arthritis. Plos One. 2012;7, e47668.

30. Xing Z, Conway EM, Kang C, Winoto A. Essential role of survivin, an inhibito of apoptosis protein, in T cell development, maturation, and homeostasis. J Exp Med. 2004:199:69-80

31. Kobayashi K, Hatano M, Otaki M, Ogasawara T, Tokuhisa T. Expression of a murine homologue of the inhibitor of apoptosis protein is related to cell proliferation. Proc Natl Acad Sci U S A. 1999;96:1457-62.

32. Turkkila M, Andersson KM, Amu S, Brisslert M, Erlandsson MC, Silfverswärd S, et al. Suppressed diversity of survivin splicing in active rheumatoid arthritis. Arthritis Res Ther. 2015;17:175.

33. Bokarewa M, Lindblad S, Bokarew D, Tarkowski A. Balance between survivin, a key member of the apoptosis inhibitor family, and its specific antibodies determines erosivity in rheumatoid arthritis. Arthritis Res Ther. 2005;7:R349-58.

34. Svensson B, Hafström I, Forslind K, Albertsson K, Tarkowski A, Bokarewa M. Increased expression of proto-oncogene survivin predicts Joint destruction and persistent disease activity in early rheumatoid arthritis. Ann Med. 2010;42:45-54

35. Isgren A, Forslind K, Erlandsson M, Axelsson C, Andersson S, Lund A, et al. High survivin levels predict poor clinical response to infliximab treatment in patients with rheumatoid arthritis. Semin Arthritis Rheum. 2012:41:652-7.

36. Ahn JK, Oh JM, Lee J, Bae EK, Ahn KS, Cha HS, et al. Increased extracellular survivin in the synovial fluid of rheumatoid arthritis patients: fibroblast-like synoviocytes as a potential source of extracellular survivin. Inflammation. 2010:33:381-8

37. Dean AG, Sullivan KM, Soe MM. OpenEpi: Open Source Epidemiologic Statistics for Public Health 2014. Updated 22/09/2014; cited 2014-2015. Available at: www.OpenEpi.com.

38. Rezaei H, Saevarsdottir S, Forslind K, Albertsson K, Wallin H, Bratt J, et al. In early rheumatoid arthritis, patients with a good initial response to methotrexate have excellent 2-year clinical outcomes, but radiological progression is not fully prevented: data from the methotrexate responders population in the SWEFOT trial. Ann Rheum Dis. 2012;71:186-91.

39. Hirano H, Maeda H, Takeuchi $Y$, Susaki $Y$, Kobayashi R, Hayashi A, et al. Association of cigarette smoking with the expression of nuclear survivin in pathological Stage IA lung adenocarcinomas. Med Mol Morphol. 2014:47:196-200 
40. Aletaha D, Smolen J, Ward MM. Measuring function in rheumatoid arthritis: Identifying reversible and irreversible components. Arthritis Rheum. 2006;54:2784-92.

41. Saevarsdottir S, Wallin H, Seddighzadeh M, Ernestam S, Geborek P Petersson IF, et al. Predictors of response to methotrexate in early DMARD naive rheumatoid arthritis: results from the initial open-label phase of the SWEFOT trial. Ann Rheum Dis. 2011;70:469-75.

42. Hambardzumyan K, Bolce R, Saevarsdottir S, Cruickshank SE, Sasso EH, Chernoff D, et al. Pretreatment multi-biomarker disease activity score and radiographic progression in early RA: results from the SWEFOT trial. Ann Rheum Dis. 2014;74:1102-9.

43. Goekoop-Ruiterman YP, de Vries-Bouwstra JK, Allaart CF, van Zeben D, Kerstens PJ, Hazes JM, et al. Clinical and radiographic outcomes of four different treatment strategies in patients with early rheumatoid arthritis (the BeSt study): a randomized, controlled trial. Arthritis Rheum. 2005:52:3381-90,

44. Moreland LW, O'Dell JR, Paulus HE, Curtis JR, Bathon JM, St Clair EW, et al. A randomized comparative effectiveness study of oral triple therapy versus etanercept plus methotrexate in early aggressive rheumatoid arthritis: the treatment of Early Aggressive Rheumatoid Arthritis Trial. Arthritis Rheum. 2012;64:2824-35.

45. Saevarsdottir S, Wedrén S, Seddighzadeh M, Bengtsson C, Wesley A, Lindblad S, et al. Patients with early rheumatoid arthritis who smoke are less likely to respond to treatment with methotrexate and tumor necrosis factor inhibitors: observations from the Epidemiological Investigation of Rheumatoid Arthritis and the Swedish Rheumatology Register cohorts. Arthritis Rheum. 2011;63:26-36.

46. Vermeer M, Kuper HH, Hoekstra M, Haagsma CJ, Posthumus MD, Brus HL, et al. Implementation of a treat-to-target strategy in very early rheumatoid arthritis: results of the Dutch Rheumatoid Arthritis Monitoring remission induction cohort study. Arthritis Rheum. 2011;63:2865-72.

47. Katchamart W, Johnson S, Lin HJ, Phumethum V, Salliot C, Bombardier C. Predictors for remission in rheumatoid arthritis patients: a systematic review. Arthritis Care Res (Hoboken). 2010;62:1128-43.

48. Umičevic Mirkov M, Cui J, Vermeulen SH, Stahl EA, Toonen EJ, Makkinje RR, et al. Genome-wide association analysis of anti-TNF drug response in patients with rheumatoid arthritis. Ann Rheum Dis. 2013;72:1375-81.

49. Plant D, Bowes J, Potter C, Hyrich KL, Morgan AW, Wilson AG, et al. Genome-wide association study of genetic predictors of anti-tumor necrosis factor treatment efficacy in rheumatoid arthritis identifies associations with polymorphisms at seven loci. Arthritis Rheum. 2011;63:645-53.

50. Lequerré T, Gauthier-Jauneau AC, Bansard C, Derambure C, Hiron M, Vittecoq $O$, et al. Gene profiling in white blood cells predicts infliximab responsiveness in rheumatoid arthritis. Arthritis Res Ther. 2006;8:R105.

51. Hueber W, Tomooka BH, Batliwalla F, Li W, Monach PA, Tibshirani RJ, et al. Blood autoantibody and cytokine profiles predict response to anti-tumor necrosis factor therapy in rheumatoid arthritis. Arthritis Res Ther. 2009;11:R76

52. Klaasen R, Cantaert T, Wijbrandts CA, Teitsma C, Gerlag DM, Out TA, et al The value of rheumatoid factor and anti-citrullinated protein antibodies as predictors of response to infliximab in rheumatoid arthritis: an exploratory study. Rheumatology. 2011;50:1487-93.

53. Khan S, Bennit HF, Wall NR. The emerging role of exosomes in survivin secretion. Histol Histopathol. 2015;30:43-50.

54. Baran M, Mollers LN, Andersson S, Jonsson IM, Ekwall AK, Bjersing J, et al. Survivin is an essential mediator of arthritis interacting with urokinase signalling. J Cell Mol Med. 2009;13:3797-808.

55. Mera S, Magnusson M, Tarkowski A, Bokarewa M. Extracellular survivin upregulates adhesion molecules on the surface of leukocytes changing their reactivity pattern. J Leukoc Biol. 2008:83:149-55.

56. DeNucci CC, Shimizu Y. beta1 integrin is critical for the maintenance of antigen-specific CD4 T cells in the bone marrow but not long-term immunological memory. J Immunol. 2011;186:4019-26.

57. Chen W, Zhu C. Mechanical regulation of T-cell functions. Immunol Rev. 2013:256:160-76

58. Yosef N, Shalek AK, Gaublomme JT, Jin H, Lee Y, Awasthi A, et al. Dynamic regulatory network controlling $\mathrm{TH} 17$ cell differentiation. Nature. 2013;496:461-8.

59. Andersson KM, Svensson MN, Erlandsson MC, Jonsson IM, Bokarewa MI. Down-regulation of survivin alleviates experimental arthritis. J Leukoc Biol. 2015:97:135-45

\section{Submit your next manuscript to BioMed Central and take full advantage of:}

- Convenient online submission

- Thorough peer review

- No space constraints or color figure charges

- Immediate publication on acceptance

- Inclusion in PubMed, CAS, Scopus and Google Scholar

- Research which is freely available for redistribution 